\title{
Differences in voice-hearing experiences of people with psychosis in the USA, India and Ghana: interview-based study
}

\author{
T. M. Luhrmann, R. Padmavati, H. Tharoor and A. Osei
}

\section{Background}

We still know little about whether and how the auditory hallucinations associated with serious psychotic disorder shift across cultural boundaries.

\section{Aims \\ To compare auditory hallucinations across three different cultures, by means of an interview-based study.}

\section{Method}

An anthropologist and several psychiatrists interviewed participants from the USA, India and Ghana, each sample comprising 20 persons who heard voices and met the inclusion criteria of schizophrenia, about their experience of voices.

\section{Results}

Participants in the USA were more likely to use diagnostic labels and to report violent commands than those in India and Ghana, who were more likely than the Americans to report rich relationships with their voices and less likely to describe the voices as the sign of a violated mind.

\section{Conclusions}

These observations suggest that the voice-hearing experiences of people with serious psychotic disorder are shaped by local culture. These differences may have clinical implications.

\section{Declaration of interest} None.
It is unclear whether the phenomenology of hearing voices by those with serious psychotic disorder may be shaped by local culture. We report here on the first structured interview-based comparison of hearing voices in three different cultures, comparing samples of 20 adults each living respectively in or around San Mateo, California, USA; Accra, Ghana; and Chennai, India. The experience of hearing voices is complex and varies from person to person. ${ }^{1} \mathrm{~A}$ demonstration of cultural variations in the kinds of relationships people report with their voices may offer a natural experiment in support of recent research suggesting that the voice-hearing experience is mutable.

\section{Method}

Participants met our inclusion criteria if different sources (interview, including the brief psychosis screen from the Structured Clinical Interview for DSM-IV Axis I Disorders, ${ }^{2}$ and, if available, medical records and clinicians' reports) together provided evidence that the person had experienced at least two positive symptoms (such as hallucinations and delusions) and had been ill for at least 1 month with prior signs of illness for at least 6 months (in most cases the participants had been ill for years) to the degree that their lives had been seriously disrupted. These are the inclusion criteria for schizophrenia. ${ }^{3}$ However, we did not rule out individuals with affective symptoms in addition to their psychosis. Many of our participants were diagnosed at some point with schizoaffective disorder, and some - particularly those in Accra - carried chart diagnoses for both bipolar disorder and schizophrenia. We also did not rule out people who reported using cannabis and other substances during the course of their illness; doing so would have sharply limited our American and African participant pool. However, we included only those who heard voices in the absence of the substance.

In San Mateo participants were recruited primarily through caseworkers at the San Mateo County Psychiatric Hospital and interviewed by T.L., an anthropologist with extensive experience among people with serious psychotic disorder. They were almost all supported by disability stipend and lived in supported housing. All had been ill for years. There were 10 men and 10 women; their average age was 43 years. In Chennai participants were recruited from the Schizophrenia Research Foundation (SCARF), where they were either receiving out-patient treatment or in long-term residential care. All had been ill for many years. They were interviewed by R.P. and H.T., senior research psychiatrists, primarily in Tamil. There were 9 women and 11 men; their average age was 41 years. In Accra participants were in-patients at the Accra General Psychiatric Hospital. They were recruited by staff following the direction of A.O., its medical director and chief psychiatrist. All were interviewed by T.L. in English, although in two cases the bulk of the interview was conducted in Twi by T.L.'s research assistant. There were 12 women and 8 men; their average age was 34 years. This group was thus younger and more seriously ill than people in the Chennai and San Mateo samples.

\section{Interview}

The interview protocol (see online Appendix DS1) began by asking the participants about the phenomenology of their hallucination experience: how many voices they heard, how often, and whether they experienced hallucinations in other sensory modalities. The interview was loosely based on the Maastricht interview developed by Romme \& Escher; ${ }^{4}$ we also consulted a series of other established interviews about voice-hearing, such as the Leudar-Thomas Voices Pragmatics Assessment Interview. ${ }^{5}$ We then asked the participants whether they knew who was speaking, whether they had conversations with the voices, and what the voices said. We asked people what they found most distressing about the voices, whether they had any positive experiences of voices and whether the voice spoke about sex or God. We asked what caused the voices and what caused their illness. Not all participants completed the full interview protocol, but all spoke about their experience in detail. All interviews were digitally recorded, transcribed and if necessary translated by a 
professional, and checked for word-for-word accuracy by a researcher competent in both English and the speaker's native language.

In all cases participants gave informed consent for the interview and the research was approved by the Stanford University institutional review board, the SCARF ethics committee and the medical director of the Accra General Psychiatric Hospital.

\section{Results}

Broadly speaking the voice-hearing experience was similar in all three settings. Many of those interviewed reported good and bad voices; many reported conversations with their voices, and many reported whispering, hissing or voices they could not quite hear. In all settings there were people who reported that God had spoken to them and in all settings there were people who hated their voices and experienced them as an assault. Nevertheless, there were striking differences in the quality of the voice-hearing experience, and particularly in the quality of relationship with the speaker of the voice. Many participants in the Chennai and Accra samples insisted that their predominant or even only experience of the voices was positive - a report supported by chart review and clinical observation. Not one American did so. Many in the Chennai and Accra samples seemed to experience their voices as people: the voice was that of a human the participant knew, such as a brother or a neighbour, or a human-like spirit whom the participant also knew. These respondents seemed to have real human relationships with the voices - sometimes even when they did not like them. This was less typical of the San Mateo sample, whose reported experiences were markedly more violent, harsher and more hated.

\section{San Mateo}

In general the American sample experienced voices as bombardment and as symptoms of a brain disease caused by genes or trauma. They used diagnostic labels readily: all but three spontaneously described themselves as diagnosed with 'schizophrenia' or 'schizoaffective disorder' and every single person used diagnostic categories in conversation. Fourteen described voices that told them to hurt other people or themselves, sometimes in disturbing detail: for example,

'Usually, it's like torturing people, to take their eye out with a fork, or cut someone's head and drink their blood, really nasty stuff.'

Five people even described their voice-hearing experience as a battle or war, as in 'the warfare of everyone just yelling'. Finally, the Americans talked about their voices as unreal thoughts in which there is a disrupted relationship between their thoughts and their mind. They said things such as,

'I don't think there's anything there or anything. I think it's just the way my mind works.'

None of the San Mateo sample reported predominantly positive experiences, although half reported some positive dimensions to the voice-hearing. These participants tended to do so as throwaway remarks. One man described his voice as mean and insulting but said, when asked if there were any voices that liked him, 'Yeah ... that's what I live for'. Then he returned to describing the voices he did not like. Five reported hearing God speak audibly, although 15 were clearly religious. Only two reported that they heard family members on a regular basis, and both these were women molested by their father (or stepfather) who heard their (negative) molester's voice. Only one person reported that she heard primarily people she knew: 'my therapist, my best friend, a friend from high school and this horrible guy'. Eight people said that they did not know who their voices were. Even when they said they knew them, the names they sometimes gave them suggested that they did not consider their voices to be human, as in 'their name is M' or 'Demon and Entity'. Few described personal relationships with their voices. The participant with the most positive experience described voices that seemed sometimes magical and sometimes horrific. For her, sounds seemed to resolve themselves into voices, so she heard voices all the time - 'I think I have friends in the wind' - but she could not really communicate with them because they spoke a language she did not know. She talked with God 'he's very nice' - but her only account of their interaction was this: 'Sometimes it seems the Lord gives me the thought and gives me the light, gives me the say-so as to have my own thoughts and have my own mind, and then sometimes he'll erase it when he wants to give it to someone else.'

Meanwhile, she emphasised the bad voices: 'Someone is like yelling loudly in my ear'.

\section{Chennai}

More than half of the Chennai sample $(n=11)$ heard voices of kin, such as parents, mother-in-law, sister-in-law or sisters. Another two experienced a voice as husband or wife, and yet another reported that the voice said he should listen to his father. These voices behaved as relatives do: they gave guidance, but they also scolded. They often gave commands to do domestic tasks. Although people did not always like them, they spoke about them as relationships. One man explained, 'They talk as if elder people advising younger people'. A woman heard seven or eight of her female relatives scold her constantly. They told her that she should die; but they also told her to bathe, to shop, and to go into the kitchen and prepare food. Another woman explained that her voice took on the form of different family members - it 'talks like all the familiar persons in my house'. Although the voice frightened her and sometimes, she clamed, even beat her, she insisted that the voice was good: 'It teaches me what I don't know'. Only four persons in the Chennai sample said that they did not know who spoke to them. These voices did not even seem particularly disembodied. At least nine Chennai participants described their voices as if the voice itself acted physically or had physical experience. For example, one man described his voices as souls in hell who needed him to ease their suffering. They complained that he dragged them along with him when he went out and that it hurt them. He said that the voices vomited when he had sex. Another man used this vivid metaphor:

'I went to Bangalore and I could hear the voices there as well, can be heard like it has been soaked and stuck to my body.'

Only four of the Chennai sample used the term 'schizophrenia'; indeed, the lesser use of diagnostic labels by patients and their families in South Asia has previously been described in the ethnographic literature. ${ }^{6}$ Only three - and occasionally a fourth - described their voices as commanding them to hurt other people or themselves (although more people than that heard voices with threatening content). Instead, what more participants (at least 13) reported as distressing about their voices was that their voices spoke about sex. Nine persons understood their voices as spirits or magical (although only six had heard a god speak audibly). Nine described voices that were significantly good, even though we judged only five to have had voice-hearing experiences that were predominantly good. They made comments that suggested that these voices were both social relationships and entertainment: 'I like my mother's voice'; later, this woman added 'I have a companion to talk [to] . . . [laughs] I need not go out to speak. I can talk within myself!' A man who in general found his voices difficult still said that they were interesting: 'I will play with my mind'. Another man, who heard two or three women he thought were wives, said, 'Voices, I like it. It will keep talking which is enjoyable.' In fact, several Indian participants seemed to experience their main voice as playful - true for none of the San Mateo or Accra group to any notable degree. One woman spoke 
excitedly about her voices as if she was living in the pages of a celebrity gossip magazine. When another woman first fell ill, she heard Hanuman, the Hindu god represented as part monkey:

'He is half monkey, half man; he is a god and he wears a red dhoti and he wears a lot of jewellery. And he carries a big stick with a big round thing because he protects people from wicked people.'

She was very clear that in the beginning he was not nice to her and was always trying to punish her. 'Such horrible orders he used to give me' - for example, to drink water from the toilet. Then he became fun. She described him as her baby brother. She said that they have parties and throw pillows and she pinches his bottom. She still heard him speak audibly.

\section{Accra}

Although many of the Accra participants understood that hearing audible voices could be a sign of psychiatric illness, their social world accepts that there are human-like non-embodied spirits that can talk. 'Voices [are] spirits,' one man explained. Only two people used diagnostic labels (schizophrenia). Only two described their voices as asking them to kill or to fight, although six who did not were admitted to the hospital because they had committed violent acts. Only four said that they did not know who spoke to them. When people talked about their voices they were likely to emphasise the positive. Fully 16 of the sample of 20 reported hearing God (or another divinity) speak audibly; the remaining four were the only interviewees who reported no positive experiences. (Because many Christians speak of 'hearing' God, we were careful to establish in the interview whether this experience was actually audible.) Fully half of the 20 described their current voice-hearing experience as entirely or primarily positive. A man admitted with terrible burns because a 'bad' voice had told him to grab a live electrical wire said that, 'Mostly, the voices are good'. A man admitted for the first time in 2007 said:

'They just tell me to do the right thing. If I hadn't had these voices I would have been dead long ago.'

It sometimes took time for participants to admit that they heard bad voices as well as good ones. One man, in and out of hospital since 1987, heard many voices speaking to him, among them God ('he's saving my life'), and they gave him helpful and protective advice. Partway through the interview it became clear that he also heard horrible voices as he walked across the ward - but God told him to ignore them, he said, so he did. 'I don't pay attention to the bad voices when they speak.' Indeed, people often insisted that their good voice (usually God) was more powerful than any bad voice. Another man had a special relationship with four river spirits who gave him authority over the domestic animals in the village, which he proceeded to kill and eat if they did not stay within certain bounds (it was this that led his village headman to send him to hospital). He heard bad voices as well, which gave him commands he did not want to follow. God, he explained, gave him the ability to call the good spirits to him, and they protected him from the bad: 'They can never come back again'. A woman told us that when God's voice became audible to her about nine months earlier, she also began to hear demons whispering behind her back every day. 'They try to tell you to do bad things.' The demons spoke more loudly than God did (other patients said this as well). But God's voice came first, and she followed him, she said. Even when the voices were bad, people often described what seems like a social relationship with them. Another woman heard 'many, many voices'. She heard God speak, but she dwelt on the two bad voices she heard more often: her husband's brother and her manager. They said, 'I like you. I want to kill you. I want to marry you. I want to kill you.' She disliked them intensely. But she held ordinary conversations with them. She talked about them as people, not as intrusive noise: 'I know them'.

\section{Discussion}

One of the most robust observations in cultural psychology and psychological anthropology is that Europeans and Americans imagine themselves as individuals; as Clifford Geertz put it:

A bounded, unique, more or less integrated motivational and cognitive universe; a dynamic center of awareness, emotion and judgment organized into a distinctive whole and set contrastively against other such wholes.

This is a claim about how people conceive of themselves as persons, not about psychological mechanism, and its point is that outside Western culture people are more likely to imagine mind and self as interwoven with others. These are, of course, social expectations, or cultural 'invitations' - ways in which other people expect people like themselves to behave. Actual people do not always follow social norms. Nonetheless, the more 'independent' emphasis of what we typically call the 'West' and the more interdependent emphasis of other societies has been demonstrated ethnographically and experimentally many times in many places among them India and Africa. ${ }^{8,9}$ For instance, the anthropologist McKim Marriott wanted to be so clear about how much Hindus conceive themselves to be made through relationships, compared with Westerners, that he called the Hindu person a 'dividual.' His observations have been supported by other ethnographers of South Asia and certainly in south India, ${ }^{11,12}$ and his term 'dividual' was picked up to describe other forms of non-Western personhood. ${ }^{13}$ The psychologist Glenn Adams has shown experimentally that Ghanaians understand themselves as intrinsically connected through relationships. ${ }^{14,15}$ The African philosopher John Mbiti remarks: 'only in terms of other people does the [African] individual become conscious of his own being. ${ }^{16}$

\section{Cultural orientations}

These examples do not add up to a single proposition, nor are they presumed to do so in the anthropological or psychological literature. Instead, the point this research makes is that relationships with others are far more salient to the ways non-Westerners (certainly South Asians and Africans) interpret their experience than they are to Westerners. We believe that these social expectations about minds and persons may shape the voice-hearing experience of those with serious psychotic disorder. Our participants in San Mateo were more likely to experience their voices as an assault. The voices were felt to be intrusions into their private world, and the sense that they could not be controlled upset them deeply. Our participants in Chennai and Accra were not as troubled by the presence of voices they could not control; they interpreted them, in effect, as people - who cannot be controlled. The voices seemed to make more sense to them, and they were more likely to say that they liked them. There were, of course, many differences between the voice-hearing experiences of those in Accra and those in Chennai - the Chennai voice-hearing experience included more playfulness and more emphasis on sex, for example, whereas the Accra voice-hearing experience was more likely to involve the dominant voice of God - but our most striking finding was that hearing voices in the two non-Western settings seemed less harsh and more relational than in San Mateo. Although our work seems to be the first interview-based structured comparison of the phenomenology of voice-hearing among people with serious psychotic disorder in three different cultures, previous anthropological and psychiatric work has also observed that the voice-hearing experience outside the West may be less harsh. ${ }^{17-20}$

These differences in experience cannot be ascribed to a difference in religiosity. Most of the Americans were religious, and the five Americans who heard God's voice did not, in general, like their voices. Many of the more pleasurable voice-hearing experiences 
in Chennai were not experiences of hearing God (although they were in Accra). Nor can the difference be ascribed to differences in urban living: almost all those interviewed were city-dwellers, and Accra and Chennai are noisier and more chaotic than San Mateo. Instead, the difference seems to be that the Chennai and Accra participants were more comfortable interpreting their voices as relationships and not as the sign of a violated mind. We suspect that the American cultural emphasis on individual autonomy shapes not only a clinical culture in which patients have the right to know, and should know, their diagnosis, but a more general cognitive bias that unusual auditory events are symptoms, rather than people or spirits.

Many years ago, in a famous paper, Jane Murphy demonstrated that serious psychotic disorder was recognised by the same behaviours in many different societies. ${ }^{21}$ Altering the social context of the illness might alter the content of hallucinations and delusions, she argued, but little else. We believe, however, that the cultural shaping may be more profound. It seems from our evidence that auditory hallucinations are not only construed differently in different cultural settings, but that their affective tone actually shifts. This is in accord with the new cognitivedevelopmental model of psychotic hallucinations, which argues that cognitive bias, as well as cognitive deficit, shapes the rate, content and phenomenology of psychotic hallucination. ${ }^{22,23} \mathrm{We}$ suggest that everyday expectations determine (to some extent) the way people attend to the messy array of auditory events that occur for most people with serious psychotic disorder and, in consequence, alter those auditory phenomena; that everyday, socially shaped expectations alter not only how what is heard is interpreted, but what is actually heard.

\section{Implications}

These findings may be clinically significant. Researchers have found that what the hallucinatory voices say affects how well the person hearing them does. ${ }^{24,25}$ They have also discovered that specific therapies may alter what patients hear their voices say. ${ }^{26,27}$ A new, primarily consumer-driven movement (the Hearing Voices Network) claims that it is possible to improve a person's relationship with their voices by teaching them to name their voices, to respect their voices and to interact with them, and that doing so reduces the voice's caustic quality. ${ }^{28}$ There is evidence that schizophrenia has a more variable outcome than once was thought and that social environment affects not only the severity but also the rate of illness. ${ }^{29}$ The finding that schizophrenia has a more benign course and outcome outside the West (in India, specifically) remains robust despite further follow-up and fresh analysis. ${ }^{30}$ Our work adds yet another hypothesis (to the many that now exist) to explain this gentler trajectory, which is that more benign voices may contribute to more benign course and outcome.

There is clearly more work to be done. Our study is limited by its small numbers, which are characteristic of qualitative work. Nevertheless, it suggests that the harsh, violent voices so common in the West may not be an inevitable feature of schizophrenia.

\footnotetext{
T. M. Luhrmann, PhD, Stanford University, Stanford, California, USA; R. Padmavati MD, H. Tharoor, DNB, MNAMS, Schizophrenia Research Foundation, Chennai, India; A. Osei, MB ChB, FWACP, Accra General Psychiatric Hospital, Accra, Ghana

Correspondence: T. M. Luhrmann, Stanford University, 441 Gerona Road, Stanford, CA 94305, USA. Email: luhrmann@stanford.edu

First received 19 Sep 2013, final revision Feb 2014, accepted 3 Apr 2014
}

\section{References}

1 Tuttle G. Hallucinations and illusions. Am J Psychiatry 1902; 58: 443-67.

2 First M, Spitzer RL, Gibbon M, Williams JBW. Structured Clinical Interview for DSM-IV-TR Axis I Disorders, Research Version, Patient Edition With Psychotic Screen (SCID-I/P W/PSY SCREEN). Biometrics Research, New York State Psychiatric Institute, 2002.

3 American Psychiatric Association. Diagnostic and Statistical Manual of Mental Disorders (4th edn, Text Rev) (DSM-IV-TR). APA, 2000.

4 Romme M, Escher S. Making Sense of Voices. Mind, 2004.

5 Leudar, I, Thomas P. The Verbal Hallucinations Pragmatics Assessment Schedule. Department of Psychology, University of Manchester, 1995.

6 Sousa A. Pragmatic Ethics, Sensible Care: Psychiatry and Schizophrenia in North India. PhD dissertation, University of Chicago, 2011.

7 Geertz C. From the 'native's point of view': on the nature of anthropological understanding. Bull Am Acad Arts Sci 1974; 28: 26-45.

8 Markus H, Mullally PR, Kitayama S. Selfways: diversity in modes of cultural participation. In The Conceptual Self in Context (U Neisser, D Jopling, eds): 13-74. CUP, 1997

9 Nisbett R. The Geography of Thought. Free Press, 2004.

10 Marriott M. Hindu transactions. In Transaction and Meaning: Directions in the Anthropology of Exchange and Symbolic Behavior: 109-42. Philadelphia Institute for the Study of Human Issues, 1976.

11 Miller J. Cultural psychology of moral development. In Handbook of Cultural Psychology (S Kitayama, D Cohen, eds). Guilford, 2006.

12 Trawick M. Notes on Love in a Tamil Culture. University of California Press, 1992.

13 Strathern M. The Gender of the Gift. University of California Press, 1988.

14 Adams G. The cultural grounding of personal relationship: enemyship in North American and West African worlds. J Person Soc Psychol 2005; 88: 948-68.

15 Ma C, Schoeneman TJ. Individualism vs. collectivism: a comparison of Kenyan and American self-concepts. Basic Appl Soc Psych 1997; 19: 261-73.

16 Mbiti J. African Religions and Philosophy. Heinemann, 1969.

17 Fortes M, Mayer D. Psychosis and social change among the Tallensi of Northern Ghana. Cah Etud Afr 1966; 6: 5-40.

18 Scott EHM. A study of the content of delusions and hallucinations in 1000 African female patients. S Afr Med J 1967; 4: 853-6.

19 Okulate GT, Jones OBE. Auditory hallucinations in schizophrenia and affective disorder in Nigerian patients. Transcult Psychiatry 2003; 40: 531-41.

20 Suhail K, Cochrane R. Effect of culture and environment on the phenomenology of delusions and hallucinations. Int J SOC Psychiatry 2002; 48: $126-38$.

21 Murphy J. Psychiatric labeling in cross-cultural perspective. Science 1976; 191: 1019-28.

22 Bentall R, Fernyhough C, Morrison A, Lewis S, Corcoran R. Prospects for a cognitive-developmental account of psychotic experiences. Br J Clin Psychol 2007; 46: 155-73.

23 Bell V. A community of one: social cognition and auditory verbal hallucinations. PLOS Biology 2013; 11: e1001723.

24 Connor C, Birchwood M. Power and perceived expressed emotion of voices: their impact on depression and suicidal thinking in those who hear voices. Clin Psychol Psychother 2013; 20: 199-205.

25 Connor C, Birchwood M. Through the looking glass: self-reassuring meta-cognitive capacity and its relationship with the thematic content of voices. Front Hum Neurosci 2013; 7: 213.

26 Jenner JA, van de Willige G, Wiersma D. Effectiveness of cognitive therapy with coping training for persistent auditory hallucinations: a retrospective study of attenders of a psychiatric out-patient department. Acta Psychiatr Scand 1998: 98: 384-9.

27 Leff J, Williams G, Huckvale M, Arbuthnot M, Leff P.Avatar therapy for persecutory auditory hallucinations: what is it and how does it work? Psychosis 2013; doi:10.1080/17522439.2013.773457.

28 Romme M, Escher S. Accepting Voices. Mind, 1993.

29 Morgan C, McKenzie K, Fearon P. Society and Psychosis. CUP, 2008

30 Hopper K, Harrison G, Janca A, Sartorius N, eds. Recovery From Schizophrenia. OUP, 2007. 